\title{
THYROID CANCER: A RETROSPECTIVE ANALYSIS
}

\author{
NG. Javan ${ }^{1}$, N. Jitendra², KH. Ibomcha Singh ${ }^{3}$, N. Phungreikan 4 , Y. Sanatomba Singh ${ }^{5}$, Wormi Sharon 6
}

${ }^{1}$ Assistant Professor, Department of Surgery, Jawaharlal Nehru Institute of Medical Sciences, Porompat, Imphal, Manipur. ${ }^{2}$ Professor, Department of Surgery, Jawaharlal Nehru Institute of Medical Sciences, Porompat, Imphal, Manipur.

${ }^{3}$ Senior Resident, Department of Surgery, Jawaharlal Nehru Institute of Medical Sciences, Porompat, Imphal, Manipur. ${ }^{4}$ Assistant Professor, Department of Surgery, Jawaharlal Nehru Institute of Medical Sciences, Porompat, Imphal, Manipur. ${ }_{5}^{5}$ Assistant Professor, Department of Surgery, Jawaharlal Nehru Institute of Medical Sciences, Porompat, Imphal, Manipur. ${ }^{6}$ Senior Resident, Department of Surgery, Jawaharlal Nehru Institute of Medical Sciences, Porompat, Imphal, Manipur.

\section{ABSTRACT}

\section{BACKGROUND}

The incidence of Thyroid cancer has been steadily increasing all over the world. The large majority of these malignancies are represented by differentiated thyroid carcinomas, such as papillary thyroid carcinoma and follicular thyroid carcinoma. With routine physical check-ups, widespread application of high-resolution ultrasonography and fine-needle aspiration biopsy contributed to an increase in the rate of preoperative diagnosis of thyroid carcinoma for the last few decades. Considering the rising incidence of thyroid cancer worldwide, the aim of our study was to find out, which type of thyroid cancer is more common in our population undergoing thyroid surgery.

\section{MATERIALS AND METHODS}

A total of 25 adult patients of either gender with solitary nodules and/or multi-nodular goitre diagnosed histologically as thyroid carcinoma were analysed in our study. A retrospective analysis was done in all patients undergoing malignant thyroid surgery at the Jawaharlal Nehru Institute of Medical Sciences, Imphal. All clinical and pathological data were recorded into a computerized database.

\section{RESULTS}

In our study, 21 patients were female and 4 patients were male with age ranging from 18 to 62 years (Mean age -45 years). The final pathological report shows 24 cases as papillary carcinoma and 1 case as follicular carcinoma.

\section{CONCLUSION}

The most common thyroid cancer occurring in our population is papillary thyroid carcinoma with more female predominance.

\section{KEYWORDS}

Thyroid Cancer, Incidence, Total Thyroidectomy, Papillary.

HOW TO CITE THIS ARTICLE: Javan NG, Jitendra N, Singh KHI, et al. Thyroid cancer: a retrospective analysis. J. Evolution Med. Dent. Sci. 2016;5(40):2456-2459, DOI: 10.14260/jemds/2016/573

\section{INTRODUCTION \\ The incidence of Thyroid cancer have been steadily increasing all over the world. ${ }^{1-4}$ Thyroid cancers are very common and account for about $1 \%$ of all human cancers. 5 There are three main types of thyroid carcinoma: Well-differentiated thyroid carcinoma, poorly differentiated thyroid carcinoma and undifferentiated thyroid carcinoma. The large majority of these malignancies are represented by differentiated thyroid carcinomas, such as papillary thyroid carcinoma and follicular thyroid carcinoma.6,7 Papillary thyroid carcinoma is the most common form of thyroid cancer accounting for $70-90 \%$ of well-differentiated thyroid malignancies. The prognosis of differentiated thyroid carcinoma is excellent with 10-year overall survival rates exceeding $90 \%{ }^{8}$}

Financial or Other, Competing Interest: None.

Submission 04-04-2016, Peer Review 29-04-2016,

Acceptance 05-05-2016, Published 19-05-2016.

Corresponding Author:

Dr. NG. Javan,

Department of Surgery,

Jawaharlal Nehru Institute of Medical Sciences,

Porompat,

Imphal East-795005,

Manipur.

E-mail:ngjavan@yahoo.co.uk

DOI: $10.14260 /$ jemds $/ 2016 / 573$
Traditionally, prognosis and survival of thyroid cancer patients depend on specific prognostic factors which include age of patients at diagnosis, size of the lesion, extrathyroidal extension of tumour and presence of distant metastases. ${ }^{9}$

Most thyroid cancers present as thyroid nodules that are either asymptomatic or associated with local cervical symptoms or lymphadenopathy. Thyroid cancers rarely present with manifestations of metastatic disease, such as a pulmonary mass or bone pain. ${ }^{10}$ Clinical features (i.e. male gender, hard and firm neck lesion, previous neck radiation treatment), nodular lesion seen on ultrasound (i.e. solid nodule with irregular margin and microcalcifications) and scintigraphy (i.e. cold nodule) are considered as risk factors for thyroid malignancy. 11-16 With routine physical check-ups, widespread application of high-resolution ultrasonography and Fine-Needle Aspiration Biopsy (FNAB) contributed to an increase in the rate of preoperative diagnosis of thyroid carcinoma for the last few decades.1,2,17

Considering the rising incidence of thyroid cancer worldwide, the aim of our study was to find out which type of thyroid cancer is more common in our population undergoing thyroid surgery.

\section{METHOD}

A total of 25 adult patients of either gender with solitary nodules and/or multi-nodular goitre diagnosed histologically as thyroid carcinoma were enrolled in our study. 
A retrospective review was conducted to all patients undergoing malignant thyroid surgery from 2010 to 2013 at the Jawaharlal Nehru Institute of Medical Sciences, Imphal, Manipur. All clinical and pathological data were recorded into a computerized database.

Collected data included gender, age, clinical features, investigations, surgical treatment, incidence of postoperative complications and final pathology. The approval of Medical Ethics was taken from Medical Ethics Committee of JNIMS and all patients signed informed consent.

Preoperative investigations like serum calcium, serum thyroid hormones, neck ultrasonography and fine needle aspiration biopsy report were included.

\section{RESULT}

In our study, 21 patients were female and 4 patients were male with age ranging from 18 to 62 years (mean age: 45 years). Neck mass was the chief complaint in all the 25 patients. Unilateral thyroid nodule was found in 20 cases, isthmus in 1 case and bilateral thyroid mass in 4 cases. Out of 20 cases with unilateral thyroid nodules, 12 cases presented with right side nodule and 8 cases with left side nodule. Two cases were found to have unilateral cervical lymph nodes enlargement. Thyroid function test shows normal range in 23 cases, hyperthyroidism in 1 case and hypothyroidism in 1 case. Both cases were treated with medication to bring it to euthyroid stage before surgery. Calcium level were within normal limit in all the 25 cases.

Ultrasound neck done in all the 25 cases shows solid nodule in 17 cases and microcalcifications in 13 cases. Fine Needle Aspiration Biopsy (FNAB) shows 19 cases of papillary carcinoma, 2 cases of follicular neoplasm, 3 cases of colloid goitre and 1 case of medullary carcinoma. Serum calcitonin was found within normal range in the case reported as medullary carcinoma by FNAB. The final pathological report shows 24 cases as papillary carcinoma and 1 case as follicular carcinoma. One case of follicular neoplasm, 3 cases of colloid goitre and 1 case of medullary carcinoma diagnosed by FNAB initially were later diagnosed as papillary carcinoma on histopathological examination.

Total thyroidectomy was done in 20 cases, total thyroidectomy with modified radical neck dissection in 2 cases and total thyroidectomy with central neck dissection in 3 cases. All the 3 cases who have undergone central neck dissection have no palpable lymph node clinically and ultrasound also did not show enlarged lymph node. Only intraoperatively the central lymph nodes were found to be enlarged, so central neck dissection was done. Postoperatively, 10 cases developed hypocalcaemia which were managed with calcium supplement. One case had persistent hypocalcaemia and required continuous calcium supplement.

\begin{tabular}{|c|c|}
\hline Sex ratio (M/F) & $4: 21$ \\
\hline Mean age (years) & 55 (18-62 years) \\
\hline Euthyroid & 23 \\
\hline Hyperthyroidism & 1 \\
\hline Hypothyroidism & 1 \\
\hline Unilateral thyroid nodule & 20 \\
\hline Bilateral thyroid mass & 4 \\
\hline Isthmus thyroid nodule & 1 \\
\hline Cervical lymphadenopathy & 2 \\
\hline Table 1: Characteristics of 25 Patients \\
with Thyroid Cancer \\
\hline
\end{tabular}

\begin{tabular}{|c|c|}
\hline Papillary carcinoma & 19 \\
\hline Follicular neoplasm & 2 \\
\hline Medullary carcinoma & 1 \\
\hline Colloid Goitre & 3 \\
\hline Table 2: Fine Needle Aspiration Biopsy \\
\hline
\end{tabular}

\begin{tabular}{|c|c|}
\hline Papillary carcinoma & 24 \\
\hline Follicular carcinoma & 1 \\
\hline \multicolumn{2}{|c|}{ Table 3: Postoperative Histopathological Diagnosis } \\
\hline
\end{tabular}

\begin{tabular}{|c|c|}
\hline Total thyroidectomy & 20 \\
\hline $\begin{array}{c}\text { Total thyroidectomy + Modified radical neck } \\
\text { dissection }\end{array}$ & 2 \\
\hline Total thyroidectomy + Central neck dissection & 3 \\
\hline Table 4: Types of Surgery \\
\hline
\end{tabular}

\begin{tabular}{|c|c|}
\hline Hypocalcaemia & 10 \\
\hline Wound infection & 1 \\
\hline Recurrent laryngeal nerve injury & $\mathrm{Nil}$ \\
\hline Table 5: Complication of Surgery \\
\hline
\end{tabular}

\section{ABBREVIATIONS}

FNAB - Fine Needle Aspiration Biopsy.

\section{DISCUSSION}

The incidence of thyroid cancer is rapidly increasing with one of the fastest rates of increase among common human cancers. ${ }^{18}$ This is primarily due to an increase in the incidence of early-stage papillary thyroid carcinoma from 3.4 to 12.5 per 100,000 people. ${ }^{19}$ Although, the main aim of our study was to know which type of thyroid cancer is more common in our population, we also included finding of clinical features, treatment and complications in our study. The mean age at presentation was 45 years and female predominance were consistent with findings from other studies. ${ }^{20,21}$ In our study, females were affected five times more than males ( $\mathrm{M}: \mathrm{F}=1: 5.2)$. Similar with other studies, neck mass was the chief complaint in all the 25 patients with unilateral thyroid nodule in 20 cases (80\%).22 Majority of our cases have normal thyroid function except for two cases; one had hyperthyroidism, another had hypothyroidism.

Previous studies have shown that thyroid cancer incidence increases with nodules associated with Grave's disease. ${ }^{23,24}$ Tamatea JA et al ${ }^{24}$ in their study showed that the malignancy rate of palpable thyroid nodules in Grave's disease is approximately $16.9 \%$. Ling Zhang et $\mathrm{al}^{25}$ have shown that papillary thyroid carcinoma and Hashimoto's Thyroiditis have close relationship, especially in a patient with high thyroid stimulating hormone. But the association between hypothyroidism and cancer risk is controversial. In our study, both the cases with deranged thyroid function were neither associated with Grave's disease nor Hashimoto's thyroiditis.

A large number of studies have demonstrated the high overall accuracy of FNAB for the evaluation of thyroid nodule, especially in patients with single thyroid nodule. ${ }^{26,27}$ This is also observed in our study, where FNAB have diagnosed thyroid cancer in 23 cases (92\%) even though the types of thyroid cancer were different in final histopathological report in two cases. However, FNAB has shown less accuracy in the evaluation of multinodular thyroid gland as 2 out of 4 cases with multiple nodular thyroid mass were initially diagnosed as colloid goitre. Kaliszewski et $\mathrm{al}^{28}$ have shown in their study that the rate of prediction of thyroid cancer by FNAB in the 
patients with solitary thyroid nodule was three times higher than that in the patients with multiple nodule.

This is important as in cases with negative FNAB result, the surgeon may perform a less radical procedure which will require another surgery for complete removal of the remaining thyroid gland. This happened in two of our cases where we have done subtotal thyroidectomy initially, as FNAB was reported as colloid goitre. Both these 2 patients underwent second surgery in the form of completion thyroidectomy. Some studies have shown that the accuracy of FNAB can be increased by correlating with Ultrasound finding and also doing FNAB under Ultrasound guidance. ${ }^{26,27}$ Brophy $\mathrm{C}$ et $\mathrm{al}^{17}$ in their study have shown that Ultrasound finding of microcalcification was associated with significant thyroid malignancy. In our study, finding of microcalcification on ultrasound were seen in 13 cases (52\%).

Many studies have shown that total thyroidectomy is undoubtedly the optimal surgical treatment for patient with thyroid cancer. ${ }^{29-32}$ In our study also total thyroidectomy were performed in 20 cases, total thyroidectomy with modified radical neck dissection in 2 cases and total thyroidectomy with central node dissection in 3 cases. There were only few surgical complications seen in our study with transient hypocalcaemia as the main complication occurring in 10 cases. Most of these cases recovered with calcium supplement. Only one patient developed parathyroid insufficiency and required continuous calcium supplement.

Our study showed higher rate of hypocalcaemia than the previous studies. ${ }^{33}$ This may be the result of 5 out of 10 cases with hypocalcaemia, which have undergone neck dissection. Hauch $\mathrm{A}$ et $\mathrm{al}^{34}$ have reported that surgical complication rates among less experienced and low-volume surgeons were higher than those in well experienced and high-volume surgeons. All the surgeries in our study were performed by experienced surgeons or were done under their supervision. Some authors have also suggested that the complication rate of total thyroidectomy is the same as that of partial thyroidectomy when surgery is performed at high-volume center. ${ }^{35,36}$ We also feel that total thyroidectomy is a safe and effective operative procedure for treatment of thyroid cancer. In our study, papillary thyroid carcinoma accounted for the vast majority of thyroid cancer seen in 24 cases, which is consistent with previous reports. ${ }^{21,37}$

\section{LIMITATIONS}

One of the drawback of our study is the lack of a long-term follow-up to know about the survival rate and recurrent disease. Another limitation is the small sample size.

\section{CONCLUSION}

From our study, the most common thyroid cancer occurring in our population is papillary thyroid carcinoma with more female predominance. Even though our study was done in a small number of patients, to our knowledge this is one of the first study done to know the common types of thyroid cancer in our population.

\section{REFERENCES}

1. Thyroid cancer: American cancer society 2014. Updated 03/20/2014; cited 2014 09/25/2014. Available at: http://www.cancer.org/cancer/thyroidcancer/detailed guide/thyroid-cancer-key-statistics.
2. Davies L, Welch HG. Increasing incidence of thyroid cancer in the United States, 1973-2002. J Am Med Assoc 2006;295(18):2164-7.

3. Colonna M, Grosclaude P, Remontet L, et al. Incidence of thyroid cancer in adults recorded by French cancer registries (1978-1997). Eur J Cancer 2002;38(13):17628.

4. Reynolds RM, Weir J, Stockton DL, et al. Changing trends in incidence and mortality of thyroid cancer in Scotland. Clin Endocrinol 2005;62(2):156-62.

5. Sherman SI. Thyroid carcinoma. Lancet 2003;361(9356):501-11.

6. Kinder BK. Well differentiated thyroid cancer. Curr Opin Oncol 2003;15(1):71-7.

7. Pasieka JL. Anaplastic thyroid cancer. Curr Opin Oncol 2003;15(1):78-83.

8. Barczynski M, Konturek A, Stopa M, et al. Prophylactic central neck dissection for papillary thyroid cancer. Br J Surg 2013;100(3):410-8.

9. Edge SB, Byrd DR, Compton CC, et al. AJCC cancer staging manual thyroid. In:. New York, NY: Springer, 2010; 7 thed:87-96.

10. Goldman L, Ausiello DA. Cecil medicine. Saunders elsevier publishers, 2007;23rd ed.

11. Alexander EK, Kennedy GC, Baloch ZW, et al. Preoperative diagnosis of benign thyroid nodules with indeterminate cytology. N Engl J Med 2012;367:705-15.

12. Bartolazzi A, Orlandi F, Saggiorato E, et al. Galectin-3expression analysis in the surgical selection of follicular thyroid nodules with indeterminate fine-needle aspiration cytology: a prospective multicentre study. Lancet Oncol 2008;9(6):543-9.

13. Trimboli $\mathrm{P}$, Guglielmi $\mathrm{R}$, Monti $\mathrm{S}$, et al. Ultrasound sensitivity for thyroid malignancy is increased by realtime elastography: a prospective multicenter study. J Clin Endocrinol Metab 2012;97(12):4524-30.

14. Heinzel A, Müller D, Behrendt FF, et al. Thyroid nodules with indeterminate cytology: molecular imaging with 99mTc-methoxyisobutylisonitrile (MIBI) is more costeffective than the afirma ${ }^{\circledR}$ gene expression classifier. Eur J Nucl Med Mol Imaging 2014;41(8):1497-1500.

15. Giovanella L, Ceriani L, Treglia G. Role of isotope scan, including positron emission tomography/ computed tomography, in nodular goitre. Best Pract Res Clin Endocrinol Metab 2014;28(4):507-18.

16. Eszlinger M, Paschke R. Molecular fine-needle aspiration biopsy diagnosis of thyroid nodules by tumour specific mutations and gene expression patterns. Mol Cell Endocrinol 2010;322(1-2):29-37.

17. Brophy C, Junna Ge, Donghui Zhao. Association between prognostic factors and clinical outcome of welldifferentiated thyroid carcinoma: a retrospective 10year follow-up study. Oncology Letters 2015;10(3):1749-54.

18. Nosé V. Familial non-medullary thyroid carcinoma: an update. Endocr Pathol 2008;19(4):226-40.

19. Davies L, Welch HG. Current thyroid cancer trends in the United States. JAMA Otolaryngol Head Neck Surg 2014;140(4):317-22.

20. Martin J Corsten, Matthew Hearn, James Ted Mc Donald, et al. Incidence of differentiated thyroid cancer in Canada by city of residence. Journal of Otolaryngology Head \& Neck Surgery 2015;44(1):36. 
21. Tom Edward N Lo, Abigail T Uy, Patricia Deanna D Maningat. Well-differentiated thyroid cancer: the philippine general hospital experience. Endocrinol Metab 2016;31(1):72-9.

22. Wang L, Xiang M, Ye B, et al. Differentiated thyroid cancer in children: a series of 29 cases. Zhonghua Er Bi Yan Hou Tou Jing Wai Ke Za Zhi 2015;50(7):573-8.

23. Fathimabeebi P Kunjumohamed, Noor B Al-Busaidi, Hilal $\mathrm{N}$ Al-Musalhi, et al. The prevalence of thyroid cancer in patients with hyperthyroidism. Saudi Med J 2015;36(7):874-7.

24. Tamatea JA, Tu'akoi K, Conaglen JV, et al. Thyroid cancer in graves' disease: is surgery the best treatment for graves' disease? ANZ J Surg 2014;84(4):231-4.

25. Ling Zhang, Hui Li, Qing-hai Ji, et al. The clinical features of papillary thyroid cancer in hashimoto's thyroiditis patients from an area with a high prevalence of hashimoto's disease. BMC Cancer 2012;12:610.

26. Tollin SR, Mery GM, Jelveh N, et al. The use of fine-needle aspiration biopsy under ultrasound guidance to assess the risk of malignancy in patients with a multinodular goitre. Thyroid 2000;10(3):235-41.

27. Coorough N, Hudak K, Jaumec JC, et al. Nondiagnostic fine-needle aspirations of the thyroid: is the risk of malignancy higher? J Surg Res 2013;184(2):746-50.

28. Kaliszewski K, Diakowska D, Wojtczak B, et al. Fineneedle aspiration biopsy as a preoperative procedure in patients with malignancy in solitary and multiple thyroid nodules. PLoS ONE 2016;11(1):29.

29. Delbridge L, Guinea AI, Reeve TS. Total thyroidectomy for bilateral benign multinodular goitre effect of changing practice. Arch Surg 1999;134(12):1389-93.
30. Barczyński M, Konturek A, Hubalewska-Dydejczyk A, et al. Five-year follow-up of a randomized clinical trial of total thyroidectomy versus dunhill operation versus bilateral subtotal thyroidectomy for multinodular nontoxic goitre. World J Surg 2010;34(6):1203-13.

31. Yoldas T, Makay O, Icoz G, et al. Should subtotal thyroidectomy be abandoned in multinodular goitre patients from endemic regions requiring surgery? Int Surg 2015;100(1):9-14.

32. Palas C, Álvarez F, Ferreira G, et al. Total thyroidectomy treatment of benign multinodular goitre. Rev Fac Cien Med Univ Nac Cordoba 2014;71:127-32.

33. Wang $\mathrm{X}$, Xing $\mathrm{T}$, Wei $\mathrm{T}$, et al. Completion thyroidectomy and total thyroidectomy for differentiated thyroid cancer: comparison and prediction of postoperative hypoparathyroidism. J Surg Oncol 2016;113(5):522-5. doi: 10.1002/jso.24159.

34. Hauch A, Al-Qurayshi Z, Randolph G, et al. Total thyroidectomy is associated with increased risk of complications for low- and high-volume surgeons. Ann Surg Oncol 2014;21(12):3844-52.

35. Efremidou EI, Papageorgiou MS, Liratzopoulos N, et al. The efficacy and safety of total thyroidectomy in the management of benign thyroid disease: a review of 932 cases. Can J Surg 2009;52(1):39-44.

36. Ho TW, Shaheen AA, Dixon E, et al. Utilization of thyroidectomy for benign disease in the United States: a 15-year population-based study. Am J Surg 2011;201(5):570-4.

37. Aschebrook-Kilfoy B, Ward MH, Sabra MM, et al. Thyroid cancer incidence patterns in the United States by histologic type, 1992-2006. Thyroid 2011;21(2):125-34. 